\title{
Commentary: The personalized medicine of cardiothoracic surgery: Delving into subpopulations identifies the right therapy for the right patients
}

\author{
Bryan A. Whitson, MD, PhD, and Michael Essandoh, $\mathrm{MD}^{\mathrm{b}}$
}

\footnotetext{
From the ${ }^{\mathrm{a}}$ Division of Cardiac Surgery, Department of Surgery and ${ }^{\mathrm{b}}$ Division of Cardiothoracic and Vascular Anesthesia, Department of Anesthesiology, Ohio State University Medical Center, Columbus, Ohio. Disclosures: Authors have nothing to disclose with regard to commercial support.

Received for publication July 22, 2019; accepted for publication July 25, 2019; available ahead of print Oct 8, 2019.

Address for reprints: Bryan A. Whitson, MD, PhD, Division of Cardiac Surgery, Department of Surgery, Ohio State University Medical Center, N-816 Doan Hall, 410 W 10th Ave, Columbus, OH 43210 (E-mail: bryan. whitson@osumc.edu).

J Thorac Cardiovasc Surg 2020;159:2310-1

$0022-5223 / \$ 36.00$

Copyright (c) 2019 by The American Association for Thoracic Surgery

https://doi.org/10.1016/j.jtcvs.2019.07.076
}

As we strive to improve the quality of care overall for our patients, we seek to tailor our medical therapies to the appropriate and specific patient populations-this is personalized medicine. In this edition of the Journal, van Diepen and colleagues ${ }^{1}$ report on a prespecified analysis of the Levosimendan in Patients with Left Ventricular Systolic Dysfunction Undergoing Cardiac Surgery Requiring Cardiopulmonary Bypass trial. ${ }^{2,3}$ In this analysis, the investigators look to unpack the prior equivalent levosimendan to placebo findings on the outcomes in patients with reduced left ventricular ejection fraction (LVEF) undergoing cardiac surgery with cardiopulmonary bypass support. The current study attempts to identify if there is a subpopulation of patients undergoing cardiac surgery with reduced LVEF who benefitted from levosimendan administration in the perioperative period.

Levosimendin is a calcium-sensitizing inodilator that has been proposed for treatment of patients with heart failure, 4,5 with sepsis, ${ }^{6-8}$ and after bypass. ${ }^{9}$ In the Levosimendan in Patients with Left Ventricular Systolic Dysfunction Undergoing Cardiac Surgery Requiring Cardiopulmonary Bypass trial population who was included, overall, they were a heterogeneous group of patients with various physiologies, most specifically in those types of surgical procedures being undertaken. In the subgroup analysis of the current population, there were lower 90-day mortality outcomes and fewer low cardiac output syndrome occurrences in patients undergoing isolated coronary artery bypass grafting (CABG). The CABG cohort consisted of $66.4 \%$ of the overall population, and this is significantly larger than other similar evaluations in which CABG was represented in a smaller proportion $(21 \%-24 \%$ in Landoni and colleagues ${ }^{10}$ ).

van Diepen and colleagues ${ }^{1}$ accounted for multiple confounders and the economic impact of these therapies,

\section{References} 2302-9.e6.

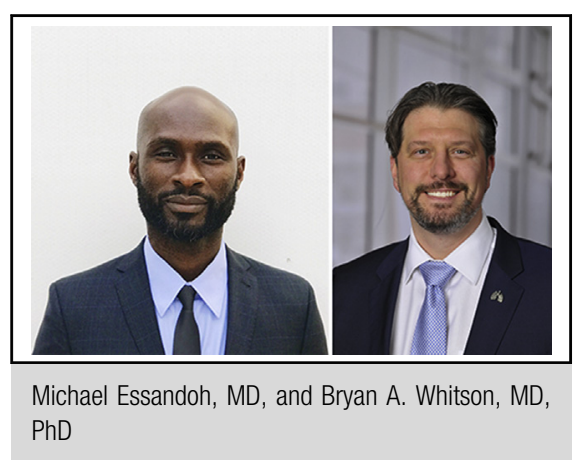

Central Message

Identifying specific patient populations who may benefit from therapies will help improve overall patient outcomes and avoid ineffectual treatment in those who may not.

See Article page 2302 .

and were able to identify a specific patient population in whom the use of levosimendin has benefit: patients with reduced LVEF undergoing CABG.

The authors are to be commended for the forethought to identify a predetermined analysis in a study of this nature in which attention to specific patient details and meticulous attention to study design are of paramount importance.

van Diepen and colleagues ${ }^{1}$ have provided us specific patient populations with specific disease indications for whom a specific therapy has benefit. It is not surprising that with the heterogeneity of our patients and the inherent complexity of the disease entities that our long-held notions of one treatment plan for all patients need to become more targeted and nuanced. The current study helps provide that clarity.

1. van Diepen S, Mehta RH, Leimberger JD, Goodman SG, Fremes S, Jankowich R, et al. Levosimendan in patients with reduced left ventricular function undergoing isolated coronary or valve surgery. J Thorac Cardiovasc Surg. 2020;159:

2. Mehta RH, Leimberger JD, van Diepen S, Meza J, Wang A, Jankowich R, et al. Levosimendan in patients with left ventricular dysfunction undergoing cardiac surgery. N Engl J Med. 2017;376:2032-42.

3. Mehta RH, Van Diepen S, Meza J, Bokesch P, Leimberger JD, Tourt-Uhlig S, et al. Levosimendan in patients with left ventricular systolic dysfunction undergoing cardiac surgery on cardiopulmonary bypass: rationale and study design of the Levosimendan in Patients with Left Ventricular Systolic Dysfunction Undergoing Cardiac Surgery Requiring Cardiopulmonary Bypass (LEVO-CTS) trial. Am Heart J. 2016;182:62-71. 
4. Silvetti S, Greco T, Di Prima AL, Mucchetti M, de Lurdes CM, Pasin L, et al. Intermittent levosimendan improves mid-term survival in chronic heart failure patients: meta-analysis of randomised trials. Clin Res Cardiol. 2014; 103:505-13.

5. Slawsky MT, Colucci WS, Gottlieb SS, Greenberg BH, Haeusslein E, Hare J, et al. Acute hemodynamic and clinical effects of levosimendan in patients with severe heart failure. Study Investigators. Circulation. 2000;102:2222-7.

6. Yang F, Zhao LN, Sun Y, Chen Z. Levosimendan as a new force in the treatment of sepsis-induced cardiomyopathy: mechanism and clinical application. J Int Med Res. 2019; 47:1817-28.

7. Bhattacharjee S, Soni KD, Maitra S, Baidya DK. Levosimendan does not provide mortality benefit over dobutamine in adult patients with septic shock: a meta-analysis of randomized controlled trials. J Clin Anesth. 2017 39:67-72.

8. Chang W, Xie JF, Xu JY, Yang Y. Effect of levosimendan on mortality in severe sepsis and septic shock: a meta-analysis of randomised trials. BMJ Open. 2018;8: e019338.

9. Rungatscher A, Linardi D, Tessari M, Menon T, Luciani GB, Mazzucco A, et al. Levosimendan is superior to epinephrine in improving myocardial function after cardiopulmonary bypass with deep hypothermic circulatory arrest in rats. J Thorac Cardiovasc Surg. 2012;143:209-14.

10. Landoni G, Lomivorotov VV, Alvaro G, Lobreglio R, Pisano A, Guarracino F, et al. Levosimendan for hemodynamic support after cardiac surgery. $N$ Engl J Med. 2017;376:2021-31. 